\title{
La Corte Constitucional y la Policía Nacional frente la actividad de los venteros ambulantes de Medellín, Colombia*
}

\author{
Clara María Mira Gonzáleza • Julián Arango Quiroz ${ }^{\mathrm{b}}$
}

\begin{abstract}
Resumen: el artículo presenta un estudio de las sentencias de la Corte Constitucional y las diferentes comprensiones de miembros de la Policía Nacional, referidas a la aplicación del test y del principio de proporcionalidad en actividad de los venteros ambulantes en Medellín, Colombia. También, se analizaron las comprensiones que algunos de los miembros de la Policía Nacional tienen frente a la aplicación del principio o test de proporcionalidad. Se concluye que las consideraciones frente a (1) la carga argumentativa que la Corte Constitucional debe realizar en sus sentencias y (2) la forma como la Policía Nacional debe aplicar el principio y el test de proporcionalidad en la actividad de los venteros ambulantes influyen en la validez de las sentencias y en la aplicación de los derechos fundamentales con carácter prioritario y, prima facie, en un Estado social de derecho como el colombiano.
\end{abstract}

Palabras clave: control constitucional; derechos fundamentales; test de proporcionalidad; máximas de optimización; venteros ambulantes

Recibido: 11 de julio de 2019 Aceptado: 18 de diciembre de 2020

Disponible en línea: 06 de agosto de 2021

Cómo citar: Mira González, C. M., \& Arango Quiroz, J. (2021). La Corte Constitucional y la Policía Nacional frente la actividad de los venteros ambulantes de Medellín, Colombia. Prolegómenos, 24(47), 11-23. https://doi.org/10.18359/ prole.4191

* Artículo de investigación, derivado del proyecto de investigación "El principio de confianza legítima frente al abuso del derecho en la actividad de los venteros ambulantes de la ciudad de Medellín. Un análisis del test de proporcionalidad", adscrito a la línea de Derecho Público, en el grupo de estudios jurídicos de la Universidad CES. El proyecto, realizado con la colaboración del Semillero de Derechos Humanos de la Universidad CES, contó con el apoyo de la Alcaldía de Medellín, en el área de gestión del conocimiento jurídico. Agradecemos a los estudiantes miembros del semillero Aldair Gámez, María Camila Hincapié, Daniel Duque y Mariana Ruiz, por todo su apoyo. También a la doctora María Soledad Gómez por animarnos a investigar este tema y abrirnos todos los espacios de divulgación.

a Abogada de la Universidad EAFIT, especialista en Estudios Internacionales y magíster en Ciencia Política de la Universidad de Antioquia, especialista en Gerencia de la Seguridad Social de la Universidad CES. Estudiante de Doctorado en Derecho de la Universidad de Antioquia. Universidad CES, Medellín, Colombia. Correo electrónico: cmira@ces.edu.co ORCID: https://orcid.org/0000-0003-1040-5944

b Estudiante de Derecho (c) de la Universidad CES, Medellín, Colombia.

Correo electrónico: arango.julian@ucesedu.onmicrosoft.com ORCID: https://orcid.org/0000-0003-1202-1514 


\section{The Constitutional Court and the National Police Against the Activity of the Street Vendors of Medellín, Colombia}

Summary: the article presents a study of the judgments of the Constitutional Court and the different understandings of the National Police, referring to the application of the test and the principle of proportionality in the activity of street vendors in Medellín, Colombia. Also, the understandings that some members of the National Police have regarding the application of the principle or test of proportionality were analyzed. It is concluded that the considerations regarding: (1) the argumentative load that the Constitutional Court must carry out in its sentences and (2) the way in which the National Police must apply the principle and the proportionality test in the activity of street vendors influence the validity of judgments and in the application of fundamental rights as priority and, prima facie, in a social state of law such as Colombia.

Keywords: constitutional control; fundamental rights; proportionality test; optimization maxims; street vendors

\section{A Corte Constitucional e a Polícia Nacional ante a atividade dos vendedores ambulantes de Medellín, Colômbia}

Resumo: neste artigo, apresenta-se um estudo das sentenças da Corte Constitucional e das diferentes compreen-
sões dos membros da Polícia Nacional, no que se refere à aplicação do teste e do princípio da proporcionalidade
em atividade dos vendedores ambulantes em Medellín, Colômbia. Além disso, são analisadas as compreensões que
alguns dos membros da Polícia Nacional têm a respeito da aplicação do princípio ou do teste de proporcionalidade.
Conclui-se que as considerações quanto à carga argumentativa que a Corte Constitucional deve realizar em suas
sentenças e à forma como a Polícia Nacional deve aplicar o princípio e o teste da proporcionalidade na atividade dos
vendedores ambulantes influenciam a validade das sentenças e a aplicação dos direitos fundamentais com caráter
prioritário e, prima facie, um Estado social de Direito como o colombiano.

Palavras-chave: controle constitucional; direitos fundamentais; teste da proporcionalidade; máximas de otimização; vendedores ambulantes 


\section{Introducción}

El test de proporcionalidad fue ideado para efectos de reforzar la carga argumentativa del juez constitucional, cuandoquiera que este tenga que decidir entre dos principios o derechos humanos de la misma jerarquía que están en colisión. Su fundamento está previsto para reforzar los argumentos en torno, primero, a los derechos humanos y, segundo, a aplicar el principio de no regresividad de dichos derechos. Esto debe ocurrir de manera que no se vea afectado el núcleo esencial de tales derechos y que el ser humano sea protegido, tanto desde su dignidad como en todas sus esferas (Corte Constitucional, Sala Plena, Sentencia C-428, 2009).

En la jurisprudencia constitucional colombiana, ha ido decantándose una comprensión de los principios, desde una ideología neoconstitucional, vigente en el Estado Social de Derecho colombiano, como fundamento propio de la Constitución. En ese sentido, se resalta el carácter de los principios como normas prima facie, en la medida en que están llamados a ser aplicados por encima de las reglas jurídicas. Por ende, están destinados a una satisfacción máxima en el Derecho colombiano.

A diferencia de las reglas, que aplican bajo una lógica de todo o nada, los principios se someten al test de ponderación o test de proporcionalidad, diseñado para resolver problemas que se presentan siempre que dos o más principios constitucionales entren en conflicto en un caso concreto.

Teniendo en cuenta lo anterior, los principios del Derecho se presentan desde una naturaleza dual: de un lado, tienen una dimensión filosófica; de otro, comportan además una dimensión jurídica. Mientras la dimensión filosófica parte de una concepción universal de los principios, incluso como pautas éticas de conducta; desde el Derecho, o desde una visión típicamente jurídica, los principios se entienden como pautas de creación, integración e interpretación de las normas jurídicas.

De este modo, la nomoárquica jurídica aporta criterios dirigidos al juez, el legislador, el jurista, el abogado y, en general, a cualquier operador jurídico, en torno a su labor creadora de Derecho, en su dimensión integradora. Tales criterios son, por un lado, fines para ser desarrollados por el Derecho, en la ley, la Constitución, la jurisprudencia y las restantes normas jurídicas; por otro, constituyen pautas interpretativas para los órganos jurídicos, particularmente para los jueces, como máximos órganos de aplicación del Derecho. Estas pautas indican, además, el modo en que los jueces deben interpretar y suplir lagunas normativas, para que, finalmente, determinen cómo superar las llamadas zonas de penumbra jurídica (Valencia, 2007).

En este sentido se resalta, entonces, el carácter de los principios como derechos fundamentales que cumplen una función de maximización u ostentan un carácter prima facie, en la medida en que están llamados a ser aplicados por encima de las reglas jurídicas y, por ende, destinados a una satisfacción máxima en el Derecho colombiano.

Como los principios son los fundamentos de la Constitución, su aplicación es inmediata. Esto es así porque de ellos derivan derechos fundamentales. A su vez, significa que cada derecho fundamental contiene un principio, es la base axiológica y jurídica que permite a la Constitución ser lo que es. Estos principios son su ontología, su ser; no son fines ni metas del Estado, funcionan a la manera de directrices y son el punto de partida del orden constitucional (Alexy, 1985; Bernal, 1993; Pozzolo, 1996; Lopera, 2004).

Las reglas, en cambio, son específicas, funcionan con una lógica del todo o nada y su estructura es condicional e hipotética. Por tanto, se componen de un supuesto de hecho y de una consecuencia jurídica. Además, no son ponderables, y ello implica que su aplicación se realiza por medio de la subsunción: a un supuesto de hecho, una consecuencia jurídica (Lopera, 2004).

En el test de ponderación existe una máxima, a la que se refiere Bernal-Pulido (2003), profesor universitario y exmagistrado de la Corte Constitucional, como máxima de optimización. Dicha máxima se explica, parafraseando al autor, en que tanto mayor es la satisfacción de un principio - o derecho fundamental - cuanto menor sea la violación de su principio en colisión.

El test de ponderación ha implicado mayor rigurosidad en el ámbito de aplicación normativa por parte del juez y, en consecuencia, un mayor control 
de las cargas argumentativas de sus sentencias. Por ende, la prueba impone - al intérprete de la Constitución, el juez constitucional, el juez de tutela o, incluso, cualquier autoridad jurídica que tenga a su cargo la decisión de derechos fundamentales - la necesidad de aplicar tres subreglas, que debe incluir en los argumentos de su decisión:

1. El juicio de adecuación, que se refiere a la existencia de un objetivo constitucionalmente válido en la prevalencia que este intérprete da al principio que está ponderando.

2. La necesidad, en este sentido, debe demostrar que el derecho fundamental que se privilegia sirve, en efecto, para estimular el objetivo constitucionalmente válido.

3. El juicio de idoneidad examina si la preponderancia de un derecho fundamental sobre otro era la menos costosa. Esto es, la más idónea y, en este sentido, se pregunta si no existían otros mecanismos que no pusieran en riesgo el derecho fundamental contrario.

Si en los casos anteriores no es posible decidir el conflicto, bien se realiza un juicio de ponderación en sentido estricto, o bien se aplica lo que Alexy (1985) denominó fórmula de peso. Esto implica que el intérprete de la Constitución debe probar o acreditar que, al elegir un principio sobre otro, no está poniendo en un riesgo alto o medio el principio contrario. Es decir, debe garantizar la aplicación de la máxima de optimización o fórmula de peso estricto, la que supone que, al priorizar la aplicación de un principio, viole lo menos posible su contrario (Bernal, 2003; Lopera, 2004).

En la Sentencia C-022 de 1996, la Corte Constitucional aclaró el sentido del test, al decidir sobre la inexequibilidad de los incentivos del Icfes en los bachilleres que prestarán el servicio militar obligatorio. Para ello, los jueces constitucionales realizaron los tres juicios planteados. Ante la pregunta de si la bonificación del $10 \%$ reconocida por la ley a los bachilleres era adecuada a la satisfacción de un fin consagrado en el ordenamiento jurídico colombiano, el juez determinó, para el caso, que existía un sinnúmero de fines dentro de la Constitución que podrían ser satisfechos frente a los incentivos del Icfes dados a los bachilleres que prestarán el servicio militar obligatorio.

Entre tales incentivos se mencionaron: la seguridad, el orden público, las buenas costumbres, la moral pública y la unidad del Estado. Todos estos fines podían ser satisfechos a través del incentivo, porque este podría estimular una mayor participación en las fuerzas armadas colombianas y, por lo tanto, incrementar la seguridad estatal. Ante esta situación, el primer objetivo de adecuación se satisfacía con una mayor unidad del Estado, una mejora del orden público. Por tanto, los fines jurídicos estarían cumplidos.

Con respecto a la segunda subregla del test de ponderación, se hace la pregunta sobre la necesidad. Esta pregunta ya no indaga acerca de la adecuación de la medida a los fines jurídicos, es decir, ya no se responde el interrogante acerca de la relación entre la norma o el Derecho y los fines del Estado. Más bien, se pregunta por la necesidad de la medida o del establecimiento de un derecho o de la protección del derecho, con respecto a dicha finalidad. En este sentido, el fin estatal o jurídico se satisface en la medida en la que logra la eficacia del fin constitucional que se propone, es decir, estimula la prestación de este servicio militar (Corte Constitucional, Sala Plena, Sentencia C-022, 1996).

No obstante, es necesario aplicar una última subregla, la regla de la ponderación en sentido estricto. Para poder desarrollarla, Carlos Gaviria Díaz, ponente de la sentencia mencionada, señala que el juicio realizado en este último requisito de la carga argumentativa es un juicio de idoneidad. En este juicio, la pregunta que se realizó el juez constitucional es si el principio privilegiado para satisfacer el objetivo constitucional, que es al mismo tiempo un objetivo constitucional válido y necesario, sacrifica, en la menor medida posible, otros fines constitucionales igualmente importantes. Por ende, la pregunta era si es realmente el más apto o si es realmente el más idóneo.

Para el caso de los incentivos del Icfes, la idoneidad de una medida discriminatoria como un incentivo del $10 \%$ en las pruebas académicas de Estado que, de manera evidente pone en riesgos los derechos a la igualdad de las mujeres y el de aquellas personas que no pueden prestar el servicio 
militar obligatorio, debe estar dada por la prueba de la "no existencia" de otros mecanismos igual de válidos y necesarios, para producir mayores ingresos de personal a las fuerzas militares. En este sentido, resultaba probado que, al existir mecanismos como la disminución de la edad pensional o mayores cotizaciones a la seguridad social en las fuerzas militares, estos no violaban otros derechos igualmente importantes en el Derecho constitucional colombiano, como los derechos de las mujeres y de los excluidos de la prestación del servicio militar obligatorio (Corte Constitucional, Sala Plena, Sentencia C-022, 1996).

Este test de proporcionalidad es, entonces, un refuerzo a la carga argumentativa del juez constitucional que pone a prueba la verdadera vigencia de los principios constitucionales dentro de la Constitución. En ese sentido, a partir de criterios de evaluación concretos, permite determinar si el intérprete constitucional surte, en efecto, las etapas necesarias, cuandoquiera que encuentre dos principios constitucionales de igual jerarquía que quisiera poner a prueba en las distintas sentencias en las que la propia Corte Constitucional ha decidido en las colisiones de principios, presentadas frente a la actividad de las ventas ambulantes.

Cuando la Corte Constitucional se ha enfrentado a la solución de casos concretos frente a la aplicación de ambos principios, como en la Sentencia T-257 de 2017, ha decidido que, para efectos de garantizar el Derecho al espacio público, es absolutamente necesario y pertinente garantizar sitios de reubicación laboral a las personas que desempeñan sus labores como venteros ambulantes, de modo que dan prevalencia al principio de confianza legítima.

En varias sentencias, se ha determinado que los derechos fundamentales prevalecen frente a los intereses sociales y colectivos y, en estos casos, la Corte Constitucional ordena a distintos órganos estatales garantizar el derecho fundamental frente a, por ejemplo, la propia función punitiva. Tal es el caso de las sentencias donde la Corte Constitucional ordena la ejecución de planes y programas para la protección de la población carcelaria en las llamadas sentencias de Estados de Cosas
Inconstitucionales (Corte Constitucional, Sala Plena, Sentencia T-153, 1998; Sentencia T-388, 2013).

Pese a ello, en otras sentencias, derechos que habían sido considerados sociales fueron privilegiados frente a derechos típicamente fundamentales; y no solo eso, sino que se sobrepusieron frente a los intereses económicos del Estado. Tal es el caso de las sentencias proferidas por la Corte Constitucional frente a la prevalencia del derecho a la salud en las crisis fiscales de las EPS. Tesis demostrada por Nubia Sabogal-Bolívar en su tesis de Maestría en Derecho en la Universidad Nacional de Colombia (2015, p. 76).

De acuerdo con las discusiones que implican una prevalencia de los principios constitucionales sobre las reglas del Derecho, resulta necesario e ineludible aplicar el llamado test de proporcionalidad a las diferentes sentencias donde se analiza la colisión de principios fundamentales en materia de ventas ambulantes en Medellín. Para ello, es necesario identificar, en principio, tres fases de este proceso, que se plantean a manera de preguntas:

a. ¿Es adecuada la elección de uno de los principios del Derecho para la satisfacción de un objetivo constitucionalmente válido, en la actividad de los venteros ambulantes de Medellín?

b. ¿Era necesaria e idónea la elección de uno u otro principio, bajo el entendido de que en las sentencias sobre este tema, debe elegirse el mecanismo más idóneo para la satisfacción del principio contrario, sin que existieran otras posibilidades de solución, menos costosas, para la restitución del derecho a los venteros ambulantes?

c. Cuando la Corte Constitucional decide frente a la prevalencia de uno u otro principio en las ventas ambulantes de la ciudad de Medellín, ¿lo hace teniendo en cuenta que su principio contrario se pone en el menor de los riesgos posibles?

La actividad de los venteros ambulantes en Medellín ha generado una tensión de principios, considerados fundamentales desde la propia Constitución. Las tensiones entre los principios que rodean la actividad de estos venteros, ocupantes y trabajadores en el espacio urbano y público son, 
entre otros, el principio de confianza legítima, el principio de abuso del derecho, el derecho al espacio público, el derecho al mínimo vital y el derecho al trabajo. El test de proporcionalidad es aplicable a la solución de los casos donde el intérprete de la Constitución debe decidir cómo iniciar acciones de reubicación laboral y de desalojo frente a aquellas personas que ejercen su derecho al trabajo en las ventas ambulantes.

La sentencia C-211 de 2017, que controló la constitucionalidad del Código de Policía en Colombia [Ley 1801 de 2016], en especial su numeral 04 y los parágrafos 02 (numeral 04) y 03 del artículo 140, consideró que las autoridades de Policía debían velar por el mantenimiento de la igualdad real y efectiva de los venteros ambulantes $y$, en este sentido,

cuando el grupo afectado con las medidas de protección del espacio público está integrado por vendedores informales, considerados [...] un sector social vulnerable, debido a sus condiciones socioeconómicas, las autoridades deben prever medidas complementarias encaminadas a mitigar los efectos negativos de su decisión; de otra manera, las políticas de protección y recuperación de estas áreas devienen injustificables a la luz de lo dispuesto por el Constituyente. (Corte Constitucional, Sala Plena, Sentencia C-211, 2017)

Por tanto, se obliga a las fuerzas de Policía a aplicar el principio de proporcionalidad en los procesos de desalojo y reubicación laboral según la Sentencia C-211 de 2017 de la Sala Plena de la Corte Constitucional, Sala Plena. Con ello, el Tribunal Constitucional facultó a una parte de las Fuerzas Armadas, órgano que tradicionalmente cumple funciones ejecutivas, para cumplir funciones típicamente judiciales, lo que al parecer desnaturaliza su función. No obstante, dado que el objetivo de la investigación está encaminado a esclarecer la aplicación del principio de proporcionalidad en la actividad de la Corte Constitucional y de la Policía de Medellín frente a los venteros ambulantes de la cuidad, se pregunta sobre el conocimiento en la fuerza pública sobre el test de proporcionalidad; también sobre la forma como la Corte Constitucional lo ha entendido y aplicado en distintas sentencias.

Para resolver este interrogante, la investigación fue realizada con una metodología de tipo mixto, en la cual se articularon los enfoques cualitativo y cuantitativo.

Primero, se realizó una lectura de las sentencias constitucionales, referidas a la actividad de los venteros ambulantes en Medellín y la forma en la que se aplicó el test de proporcionalidad. La lectura se basó en un tipo de investigación descriptiva, explicativa y hermenéutica, para identificar la aplicación por parte de la Corte Constitucional del test de proporcionalidad en la actividad mencionada.

Segundo, se realizaron dieciocho (18) encuestas a miembros de las fuerzas de policía en Medellín, para identificar si comprenden el significado del test de proporcionalidad y, con base en ello, determinar su capacidad para aplicarlo en acciones de desalojo y de reubicación laboral. Las encuestas fueron tabuladas y se elaboraron tablas estadísticas para cuantificar las respuestas, frente a la comprensión del test, y su apropiación y aplicación.

El artículo está dividido en dos secciones, que corresponden los dos momentos investigativos: la primera explora las distintas sentencias constitucionales relacionadas con la actividad de los venteros ambulantes en Medellín; la segunda analiza los hallazgos frente a las comprensiones del test de proporcionalidad entre los miembros encuestados de la Policía Nacional. Por último, se dan a conocer las conclusiones de nuestro análisis.

\section{La Corte Constitucional frente a la actividad de los venteros ambulantes en Medellín}

Como anticipamos, en la jurisprudencia constitucional colombiana, ha ido decantándose una comprensión de los principios, desde una ideología neoconstitucional, vigente como fundamentos propios de la Constitución. En este sentido, se resalta el carácter de los principios como normas prima facie, llamados a aplicarse por encima de las reglas jurídicas y destinados, por ende, a la 
máxima satisfacción en el Derecho colombiano. Además, a diferencia de las reglas, los principios se someten al test de ponderación, en el que se aplica la máxima, según la cual, tanto mayor es la satisfacción de un principio o derecho fundamental cuanto menor sea la violación de su principio en colisión (Bernal, 2003).

La aplicación del test implica mayor rigurosidad frente a la carga argumentativa de parte de los operadores constitucionales. En consecuencia, hay un control mayor de la validez de sus sentencias, control representado en la necesidad de aplicar las subreglas constitucionales de adecuación, necesidad, idoneidad y ponderación, en sentido estricto, en los argumentos de su decisión.

Los casos donde la Corte Constitucional se ha enfrentado con colisiones de principios en la actividad de los venteros ambulantes de Medellín son dos. Aunque existe gran número de casos referidos al espacio público en la jurisprudencia colombiana, solo dos abordan temas relativos a la actividad de los venteros ambulantes; ambos se refieren a acciones de tutela, contenidos en las sentencias T-775 de 2009 y T-692 de 2016 de la Corte Constitucional.

\section{La Sentencia T-775 de 2009}

En esta sentencia, la Corte Constitucional se enfrentó al siguiente problema jurídico: una petición de reubicación laboral, presentada por el ciudadano Jesús González Valdez, en la que, mediante acción de tutela, alegaba la vulneración de sus derechos laborales, por encontrarse en una situación de discapacidad, en su condición de ventero ambulante.

La Corte decidió negar la tutela y no reconocer la petición del accionante. Este alegó (1) tener un permiso adjudicado por la Alcaldía de Medellín desde hacía varios años; (2) sufrir de una situación de discapacidad que le impedía conseguir otro trabajo y (3) que sus hijos, profesionales universitarios, dependen de él económicamente. También añadió que percibía una pensión de invalidez. En la argumentación, la Corte Constitucional tampoco consideró la condición de quien reclamaba el derecho, pues ya recibía una pensión de invalidez.

La Corte entiende la proporcionalidad como unarelaciónentrelasaccionesestatalesencaminadas a proteger el espacio público y el derecho al trabajo del accionante; y no existen juicios relativos ni a la adecuación, ni a la necesidad, ni a la ponderación en sentido estricto o la idoneidad. No obstante, en esta sentencia existe una definición del principio de abuso del derecho, al considerarlo "un mecanismo para conciliar el conflicto entre los intereses público y privado, cuando la administración ha creado expectativas favorables para el administrado, y luego lo sorprende al eliminar, súbitamente, esas condiciones" (Corte Constitucional, Sala Novena de Revisión, Sentencia T-775, 2009).

El tribunal constitucional se concentró en el análisis legal y, por ello, consideró que la retoma del espacio público por la administración debía hacerse habiendo agotado los recursos internos.

Por ello, concluyó que la administración

solo podrá revocar sus actos o hechos con el previo agotamiento de los procedimientos que, para el efecto, haya previsto la ley. Sin embargo, la aplicación del principio de confianza legítima no puede entenderse como una licencia irrestricta que permita a la administración realizar cambios sorpresivos o repentinos que desconozcan derechos fundamentados o situaciones particulares. (Sentencia T-775, 2009)

La sentencia finaliza el debate declarando exequible el artículo demandado, referido a la protección del espacio público. En este sentido, prohíbe las ventas ambulantes a las personas que no se encuentren en situaciones de debilidad manifiesta, o a grupos de protección especial. Ambas consideraciones deben ser valoradas, de acuerdo con la Corte Constitucional, por los órganos de la policía.

\section{La Sentencia T-692 de 2016}

En esta sentencia, la Sala Novena de Revisión de la Corte Constitucional se enfrentó al siguiente problema jurídico: la solicitud de reubicación laboral para ejercer la actividad de las ventas ambulantes de las señoras Gladis Andrea Muñoz Franco y Luz 
Marina Gay Isaza, en el sector de La Isla conocido como "La Asomadera", ubicado en Medellín, sector Las Palmas; por la violación de sus derechos al debido proceso, a la defensa, al trabajo, al mínimo vital y a la vida digna. En este caso, la Corte Constitucional accedió a la tutela y reconoció el derecho a la reubicación laboral de las accionantes.

Las demandantes alegaban que la Alcaldía de Medellín había violado los derechos mencionados, en tanto ellas se dedicaban a las ventas ambulantes desde hacía más de veinte años y sostenían hogares compuestos incluso por personas con discapacidades, con salud deteriorada y menores de edad. Las accionantes no aportaron, dentro del caso, los permisos respectivos para el ejercicio de las ventas ambulantes.

De otro lado, la Alcaldía de Medellín señaló que existía "urgencia manifiesta" en el terreno, que obligaba a intervenir la zona (por concepto del Departamento Administrativo de Gestión del Riesgo de Desastres -DAGRD), por el riesgo de que el terreno se viniera abajo. Asimismo, señaló que los venteros ambulantes ejercían su actividad en condiciones de insalubridad, dado que no contaban con agua potable y vertían aguas negras al terreno.

El aparte donde el juez constitucional aplicó el principio de proporcionalidad está relacionado con el siguiente párrafo, en consideración a la forma como deben entenderse las políticas públicas. Consideró entonces que dichas políticas,

han de partir de una evaluación razonable y cuidadosa de la realidad sobre la cual dichas autoridades efectuarán su intervención, y formularse de manera tal que atiendan a los resultados fácticos, derivados de la evaluación en cuestión, no a un estado de cosas ideal o desactualizado, en forma tal que no se afecte indebidamente el goce efectivo de los derechos fundamentales de las personas. En otras palabras, al momento de su formulación y ejecución, se deben haber estudiado, en lo que sea técnicamente posible, todas las dimensiones de dicha realidad que resultarán afectadas por la política, programa o medida en cuestión, incluida la situación de las personas que verán sus derechos severamente limitados, a quienes se deberá ubicar, por consiguiente, en una posición tal que no queden obligados a soportar una carga pública desproporcionada; con mayor razón si quienes se encuentran afectados por las políticas, programas o medidas pertinentes están en situación de especial vulnerabilidad y debilidad por sus condiciones de pobreza o precariedad económica: frente a estas personas o grupos se deberán adelantar, en forma simultánea a la ejecución de la política en cuestión, las medidas necesarias para minimizar el daño recibido, de tal manera que se respete el núcleo esencial de su derecho al mínimo vital y a la subsistencia en condiciones de dignidad. (Corte Constitucional, Sala Novena de Revisión, Sentencia T-692, 2016)

Ahora, frente al análisis de los derechos en colisión, la Corte Constitucional, decidió en privilegio de la salubridad pública; sin tener en cuenta su adecuación a un objetivo constitucionalmente válido, la necesidad de privilegiar este derecho y su idoneidad. Se trata también de un derecho que, en principio, no es considerado fundamental, dado que se ubica en los llamados derechos de segunda generación, no destinados a ser maximizados desde la propia Constitución (art. 93).

Por ende, la Corte Constitucional no se pronunció, en este caso, ni sobre la violación de derecho fundamental alguno, ni aplicó el test de ponderación. En cambio, realizó un juicio al parecer mucho más enfocado en la legalidad de la acción administrativa que, si bien involucró un análisis de la política pública y la aplicación del principio de proporcionalidad, no aplicó, en ninguno de sus apartes, las subreglas constitucionales del test de ponderación. Asimismo, en el análisis realizado, es evidente un privilegio del principio de salubridad pública frente a los derechos fundamentales alegados por las accionantes.

\section{La policía nacional y sus comprensiones del test y principio de proporcionalidad: estudio preliminar}

Con base en una metodología cuantitativa, los autores realizaron dieciocho (18) encuestas, compuestas de diez preguntas entre miembros de la Policía de Medellín, ubicados en el sector de Buenos Aires, sobre su comprensión y aplicación del test de proporcionalidad y la actividad de los venteros 
ambulantes. Lo anterior, teniendo en cuenta las facultades conferidas en la sentencia C-211 de 2017, que se pronunció sobre la acción de inconstitucionalidad interpuesta al Código de Policía [Ley 1801 de 2016] (figuras 1-5 y tablas 1-5; los detalles de las encuestas se encuentran en los anexos).

¿Conoce usted cuáles son los requisitos que se aplican por parte de la Corte Constitucional para la valoración de la actividad de los venteros ambulantes en Medellín? (18 respuestas)

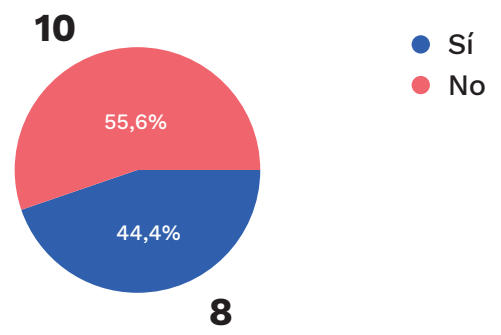

Figura 1. Conocimiento de los miembros de la Policía Nacional en torno al principio de ponderación en cuanto a ventas ambulantes.

Fuente: elaboración propia.

¿Usted, como servidor público, en alguna ocasión, ha tenido que ordenar un desalojo o reubicación laboral de un ventero ambulante? (18 respuestas)

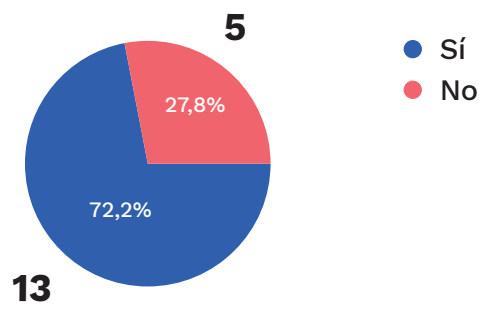

Figura 2. Ordenes de desalojo o reubicación temporal ordenadas por la Policía Nacional.

Fuente: elaboración propia.
¿Sabía usted que en los casos en los cuales usted bebe ejecutar órdenes de desalojo o reubicación laboral, debe observar el principio de proporcionalidad? (18 respuestas)

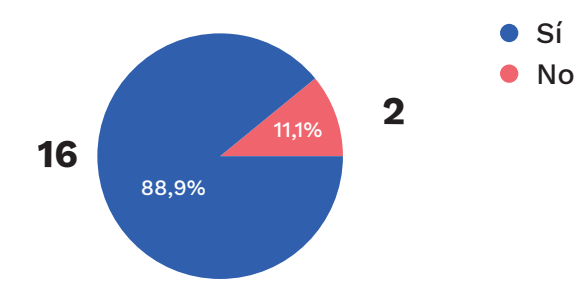

Figura 3. Conocimiento del principio de proporcionalidad, aplicado a órdenes de desalojo o reubicación laboral, por miembros de la Policía Nacional.

Fuente: elaboración propia.

¿Cree que existen circunstancias específicas que dan lugar a la aplicación del principio de proporcionalidad? (18 respuestas)

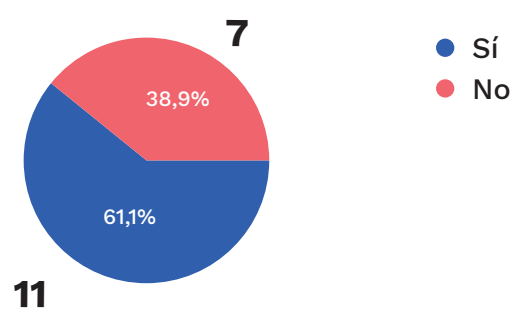

Figura 4. Conocimiento de circunstancias específicas en que se aplica el principio de proporcionalidad.

Fuente: elaboración propia.

¿Considera usted que la Policía debe aplicar el test de proporcionalidad en una circunstancia donde examine la posibilidad del desalojo o la reubicación laboral de un ventero ambulante? (18 respuestas)

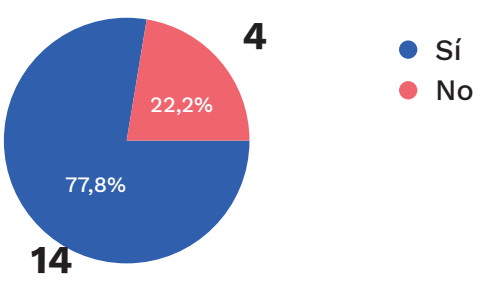

Figura 5. Percepción sobre la necesidad de que miembros de la Policía apliquen el test de proporcionalidad. Fuente: elaboración propia. 
Tabla 1. ¿Qué entienden los miembros de la Policía Nacional por "principio de proporcionalidad"?

\begin{tabular}{|l|}
\hline Igualdad, equidad \\
\hline $\begin{array}{l}\text { Trato prioritario, teniendo en cuenta las necesidades } \\
\text { particulares y generales }\end{array}$ \\
\hline $\begin{array}{l}\text { Buen trato, derecho a la información y puesta en conocimiento } \\
\text { de la acción }\end{array}$ \\
\hline Seguridad, orden público y uso de la fuerza de ser necesario \\
\hline Sentido de igualdad \\
\hline Condiciones de uno a uno \\
\hline Brindar seguridad a la población \\
\hline Misma fuerza de acción \\
\hline Es un derecho y un deber \\
\hline Beneficios proporcionales para los involucrados \\
\hline Mirar las circunstancias particulares \\
\hline Balanza y equilibrio \\
\hline Necesidad de actuar \\
\hline Otorgar seguimiento tanto a la población como al \\
funcionamiento \\
\hline Aplicación correcta del deber \\
\hline Mismo nivel \\
\hline Igualdad \\
\hline
\end{tabular}

Fuente: elaboración propia.

Tabla 2. ¿Podría indicar cómo procedió para la ejecución de la orden? Es decir, ¿cuál fue el procedimiento que usted utilizó para ejecutar esta orden de desalojo o de reubicación laboral?

\begin{tabular}{|l|}
\hline Orden, inspección y acompañamiento \\
\hline Labor de seguridad, integrantes, espacio público \\
\hline Después de la orden, la ejecución, \\
\hline Solo acompañamiento a funcionarios de la alcaldía \\
\hline $\begin{array}{l}\text { Orden, continuando con el respectivo proceso que va desde el } \\
\text { tiempo del aviso y pasado ese, el uso de otros medios }\end{array}$ \\
\hline Seguridad, manejo del orden público \\
\hline Función de acompañamiento \\
\hline $\begin{array}{l}\text { Procedimiento, orden de trabajo, tras estudio de los lugares } \\
\text { puntuales }\end{array}$ \\
\hline Seguridad y acompañamiento \\
\hline Meramente labores de acompañamiento \\
\hline
\end{tabular}

Nosotros solo nos encargamos de que no vayan a existir problemas entre los vendedores y los de espacio público

La orden llega del superior, y nosotros brindamos seguridad

Vamos y acompañamos al de espacio público en sus labores, luego, si no cumple, se nos entrega una orden distinta; no podemos sin orden

Fuente: elaboración propia.

Tabla 3. ¿Cómo debería aplicarse el principio de ponderación?

Con orientación y la sugerencia de un grupo especial dedicado solo a eso

Capacitación a líderes y patrulleros

Siguiendo el procedimiento que ordena la ley

El problema es que se siguen ordenes de un superior, contradecirlas significa omisiones y, por tanto, sanciones

Reubicando a los vendedores

Ahí sí me corchó (tras la explicación, la respuesta fue) No sabría contestar

Mediante trabajo conjunto

Con la ley

Es básico, no podemos excedernos, debemos estar en las mismas condiciones

No se puede desconocer

Otorgando permisos a los vendedores que muchas veces están dispuestos a pagar y reubicándolos donde sea posible

Como policías, debemos tener en cuenta todo el tiempo todos los factores

Con la correcta instrucción y autonomía

Fuente: elaboración propia.

Tabla 4. Describa brevemente cuáles son esas circunstancias

Dependiendo del caso específico, se aplica o no

Cuando exista necesidad del uso de la fuerza

A veces, evaluando las condiciones de una persona

No en todos los casos se debe observar, solo en los que exista peligro de un derecho

Hay casos muy evidentes

Depende de si tengo que usar la fuerza o no

Las situaciones de riesgo

Hay que mirar cada caso, no es lo mismo una reubicación que un desalojo 


\begin{tabular}{|l|}
\hline No es para todos los casos \\
\hline Depende de muchos factores (no especifica) \\
\hline Hay que evaluar los derechos en juego \\
\hline Fuente: elaboración propia.
\end{tabular}

Tabla 5. ¿Por qué lo considera?

\begin{tabular}{|l|}
\hline No me corresponde \\
\hline Falta de competencia \\
\hline Eso le toca a los de espacio público \\
\hline La policía solo acompaña \\
\hline Fuente: elaboración propia.
\end{tabular}

\section{Conclusiones y discusión}

Con base en el primero de los objetivos del proyecto -identificar las sentencias de la Corte Constitucional referidas al test de proporcionalidad en la actividad de los venteros ambulantes de Medellín-, pudieron identificarse solo dos sentencias: Sentencia T-775 de 2009 y la T-692 de 2016.

Conforme con el segundo objetivo, con respecto a la forma como la Corte Constitucional aplica el test de proporcionalidad en dichas sentencias, la conclusión es que el test de proporcionalidad establece los criterios mediante los cuales deben ponderarse los principios en colisión en casos específicos $\mathrm{y}$, con ello, maximizar el principio con mayor relevancia para garantizar la validez de la sentencia y la máxima de proporcionalidad.

No obstante, en los eventos en los que es examinada de manera preliminar la labor de la Corte Constitucional (Sentencias C-775 de 2009 y C-692 de 2016), se observa que el Tribunal Constitucional no aplicó el precedente establecido frente a la subreglas constitucionales que deben aplicarse en los casos de los venteros ambulantes de Medellín. Tales subreglas son:

1. Determinación de la finalidad constitucional imperativa en la medida.

2. Relación de medio fines en la medida perseguida y, en este sentido, la necesidad de determinar si la medida interpuesta por la Policía si satisface efectivamente la finalidad propuesta constitucionalmente.

3. Determinación de la necesidad e idoneidad de la medida.
4. No afectación del contenido mínimo del derecho social comprometido.

5. La identificación de un beneficio mayor alcanzado con la medida interpuesta frente al costo que debe aparejar.

Persiste todavía la necesidad de realizar un análisis con sujeción a la legalidad y una ausencia de consideración de los principios con carácter prima facie, esto es, como máximas de ponderación. Se mezclan derechos colectivos, no relacionados con máximas fundamentales para decidir casos concretos.

Bajo este entendido, el Derecho de la Corte pierde certeza, pero no solo pierde certeza en sus sentencias, sino también el concepto de Derecho, que es el de atajar la voluntad política o el de impedir que la voluntad de quien lo decide se desate de tal forma que se vuelva arbitrario a la manera de un cierto derecho sin controles, no porque lo que diga el intérprete de la Constitución no encuentra forma de sustentarse jurídicamente, sino porque la manera en que lo dice no encuentra un método que satisfaga la validez de la carga argumentativa.

Con respecto al tercer objetivo - analizar las comprensiones que se tienen por parte de algunos miembros de la Policía en Medellín sobre el test de proporcionalidad y su capacidad de aplicación frente a órdenes de desalojo y reubicación laboral-, los siguientes fueron los hallazgos en las encuestas realizadas a los dieciocho miembros de la Policía de Medellín:

1. Frente a la primera pregunta, relativa al conocimiento de los requisitos aplicados por la Corte Constitucional frente al test de proporcionalidad, diez miembros de la Policía Nacional señalaron que no los conocían; y solo ocho indicaron conocerlos.

2. En cuanto a la pregunta sobre la forma de entender el concepto de proporcionalidad, las respuestas fueron variadas. Algunos oficiales contestaron que estaba asociado a la igualdad, otros que al trato prioritario teniendo en cuenta necesidades particulares y generales, otros hicieron referencia al buen trato y al derecho a la información de la comunidad y a la puesta en conocimiento de la acción; también a la seguridad, al orden público y al uso 
de la fuerza; a la igualdad de condiciones, al mismo nivel y a la aplicación correcta del deber.

La mayoría de estas respuestas estuvieron enfocadas al mantenimiento del orden público; lo que es lógico dentro de las funciones de la fuerza pública. Las respuestas relativas a la razonabilidad de una acción ponderando derechos en riesgo y priorizando derechos fundamentales, no fueron las más recurrentes. La aplicación de la fuerza y el mantenimiento del orden son asociados por los miembros de la policía con la proporcionalidad.

Frente a la tercera pregunta, en la que se preguntó sobre la ejecución de órdenes de desalojo o de reubicación laboral, la mayoría de las respuestas destacan que los miembros de la Policía encuestados, por lo regular, han tenido que ejecutar estas órdenes y, por tanto, se ven abocados a aplicar el test. Solo cinco personas contestaron que no, y trece, que sí.

Respecto a la cuarta pregunta, asociada al conocimiento de la necesidad de aplicar el test de proporcionalidad en las órdenes de desalojo y de reubicación laboral, las respuestas fueron sorprendentes, en la medida en que la mayoría de los miembros de la Policía encuestados conoce esta competencia otorgada por la Corte Constitucional; y solo dos desconocen esta competencia. No obstante, las comprensiones del principio divergen.

En cuanto a la quinta pregunta, referida al procedimiento que debía aplicarse al ejecutar la orden de desalojo y de reubicación laboral, las respuestas indican solamente el proceso ejecutivo para llevarla a cabo. Es decir, se excluyen las consideraciones previas que deben tenerse en cuenta para ejecutarla o para dejar de ejecutarla. Así las cosas, las respuestas en este punto van desde el acompañamiento de la orden del inspector, hasta su ejecución, en compañía de los funcionarios de espacio público.

La sexta pregunta indagó sobre las circunstancias específicas para aplicar el test de proporcionalidad. En este sentido, se pregunta sobre si se conocen circunstancias específicas en las cuales deba aplicarse el test de proporcionalidad. Las respuestas fueron del siguiente orden: siete policías contestaron que no conocen dichas circunstancias, y once respondieron que sí las conocen.
La séptima pregunta, asociada a la anterior, se hizo bajo el entendido de que sí se conocen las circunstancias en que se aplica este test y su procedimiento y es posible identificar cuáles serían estas circunstancias. A pesar de que once miembros de la policía manifestaron conocer las circunstancias para aplicar el test de proporcionalidad, cuando se pidió identificarlas, las respuestas no se sujetan a lo esperado; además, los miembros de la Policía no suponen que en todos los casos en que opera una orden de desalojo deben aplicar el principio. En las respuestas referidas a situaciones de riesgo, se contestó que, en casos concretos, se aplica o no. En general, las respuestas son genéricas.

La octava pregunta, relacionada con la forma en la que debería aplicarse este test y las respuestas, evidencia su desconocimiento. Los encuestados respondieron que el test debía aplicarse con la orientación de un grupo especial o con el otorgamiento de permisos a los vendedores para ejercer la labor, con una correcta instrucción y autonomía. En ningún caso fueron reconocidas las subreglas de adecuación, necesidad, idoneidad y proporcionalidad en sentido estricto que debía acompañar esta aplicación.

En la novena pregunta se indagaba sobre el deber de aplicación del test tanto en un desalojo como en una reubicación laboral. En ella, las respuestas fueron del siguiente orden: cuatro personas contestaron que sí existe un deber; y catorce afirmaron que no existe tal deber. Lo anterior evidencia el incumplimiento de la competencia conferida en la sentencia C-211 de 2017; asimismo deja claro un desconocimiento de las funciones otorgadas a los miembros de la fuerza pública en la forma como deben actuar frente a las ventas ambulantes.

Finalmente, preguntamos a los miembros de la fuerza pública que contestaron que no era necesario aplicar un test de proporcionalidad en las órdenes de desalojo y de reubicación, cuáles eran las razones por las cuales no lo consideraban necesario. En esta respuesta, se hizo más evidente el desconocimiento de la función otorgada. Lo anterior, dado que todos contestaron que la Policía no era competente, que esta solo acompañaba el desalojo, que no le correspondía y que esta era una función que le competía a la Oficina de Espacio Público. 
La interpretación de los resultados frente al tercer objetivo refleja, de un lado, un grave error por parte de la Corte Constitucional en conferir atribuciones a la Policía Nacional frente a una actividad típicamente judicial; de otro, la puesta en riesgo de derechos fundamentales de los venteros ambulantes y de la Alcaldía de Medellín. Ello, en la medida en la que una falta de aplicación del test de proporcionalidad o una aplicación indebida por una autoridad que no es realmente la competente pone en riesgo los principios constitucionales fundamentales de la Carta Política, y atenta contra la confianza legítima, contra el abuso del derecho, contra el mínimo vital o bien contra el espacio público.

La argumentación de la decisión y su consideración previa, bajo los parámetros de adecuación, necesidad, idoneidad y ponderación en sentido estricto, no es un procedimiento solo formal que no ponga en riesgo la validez y contenido de la Constitución. El proceso para aplicar un desalojo o una reubicación permite dar validez y poner en vigencia la Constitución en todos sus escenarios y, en este caso, garantiza que sean maximizados los principios constitucionales, bien sean en favor de la entidad pública -Alcaldía de Medellín- o de particulares — venteros ambulantes-.

\section{Referencias}

Alexy, R. (1985). Teoría de los derechos fundamentales. Casa del Libro.

Amado, J. A. (2018). Sobre el neoconstitucionalismo y sus precursores. http://www.geocities.ws/jagamado/pdfs/ NEOCONSTITUCIONALISMO.pdf

Bernal, C. (1993). La ponderación como método para interpretar los derechos fundamentales. En E. Cáceres, I. Flores y J. Saldaña (Coord.). Problemas contemporáneos de filosofía del derecho (pp. 17-35). Universidad Autónoma de México.
Congreso de Colombia (2016, 29 de julio). Por la cual se expide el Código Nacional de Policía y convivencia [Ley 1801]. https://www.policia.gov.co/sites/default/files/ ley-1801-codigo-nacional-policia-convivencia.pdf

Corte Constitucional de Colombia, Sala Plena (1996, 23 de enero). Sentencia C-022 de 1996 [MP Carlos Gaviria Díaz]. http://www.corteconstitucional.gov.co/relatoria/1996/C-022-96.htm

Corte Constitucional de Colombia, Sala Plena (2009, 01 de julio). Sentencia C 428 de 2009 [MP Mauricio González Cuervo]. http://www.corteconstitucional.gov.co/ relatoria/2009/c-428-09.htm

Corte Constitucional de Colombia, Sala Novena de Revisión (2009, 29 de octubre). Sentencia T 775 de 2009 [MP Jorge Iván Palacio Palacio]. http://www.corteconstitucional.gov.co/relatoria/2009/T-775-09.htm

Corte Constitucional de Colombia, Sala Novena de Revisión (2016, 12 de diciembre). Sentencia T 692 de 2016 [MP Luis Ernesto Vargas Silva]. http://www.corteconstitucional.gov.co/relatoria/2016/t-692-16.htm

Corte Constitucional de Colombia, Sala Plena (2017, 05 de abril). Sentencia C 211 de 2018 [MP Iván Humberto Escrucería Mayolo]. http://www.corteconstitucional. gov.co/relatoria/2017/C-211-17.htm

Corte Constitucional de Colombia, Sala Cuarta de Revisión (2017, 27 de abril). Sentencia T 257 de 2017 [MP Antonio José Lizarazo Ocampo. http://www.corteconstitucional.gov.co/relatoria/2017/t-257-17.htm

Lopera, G. (2004). Los derechos humanos como mandatos de optimización. Doxa. Cuadernos de Filosofía del Derecho, 27, 211-246.

Pozzolo, S. (1998) Neoconstitucionalismo y especificidad de la interpretación constitucional [Trad. J. M. Vilajosana]. Cuadernos Doxa, 2(21), 339-353. https://doi. org/10.14198/DOXA1998.21.2.25

Sabogal, A. (2015). La colisión de principios en la jurisprudencia de la Corte Constitucional colombiana [Tesis de maestría, Universidad Nacional de Colombia]. Repositorio institucional UN. http://bdigital.unal.edu. co/50817/1/1032383213.2015.pdf

Valencia, H. (1993). Nomoárquica jurídica o los principios generales del derecho. Temis. 